\title{
CAPÍTULO $v$
}

\section{El borde urbano: límite virtual sobre la fragilidad rural}

\author{
Tomás Neu * \\ Laura Zimmermann*
}

"La función del proyecto urbano es intentar reorganizar y consolidar texturas, logrando nuevas conexiones, dándole carácter a la alteración, fortificando lugares con identidad, dándole fuerza o creando nuevas centralidades, incorporando inversiones previas que den a la periferia equipamientos de prestigio".

Jorge Mario Jáuregui

"Las fronteras son siempre permeables". Charles Holcombe, Una historia de Asia oriental

* Arquitecto con maestría en Estudios y Gestión del Desarrollo (Colombia). Investigador sobre el tema de bordes, paisaje intermedio y vivienda social. Docente.

** Politóloga con maestría en Estrategias Urbanas y Rurales (Francia y Reino Unido), especialista en Mercados y Políticas de Suelo en América Latina (Colombia). Consultora y docente en temas urbanos. 


\section{Introducción}

La temática de este escrito considera tres asuntos conexos: las centralidades y periferias; el paisaje intermedio, y el borde urbano. Temas que se toman de la mano, pero no se aman; no conversan y mucho menos se miran. Convergen y conviven entre sí. En esa convivencia, contextualizan y generan disimilitudes, y establecen una espacialidad común: el crecimiento urbano que genera ocupación del territorio, produce desarraigos y segregación social, transgrede contra la sostenibilidad y el medio ambiente. De igual manera, ilustran funcionalidades que promueven el desarrollo y suscitan dinámicas sobre lo político, económico, social y cultural; narrativas y hechos concretos del devenir, de lo urbano y de sus habitantes. Mientras que las centralidades se ven deterioradas, discursos urbanos arremeten contra la periferia considerada como la menos favorecida debido a su lejanía a los centros de producción; es sinónima de asentamientos informales, déficit de bienes y servicios, y movilidad compleja y deficiente. Su localización alejada de administraciones centrales sobrepasa los límites virtuales establecidos, y arremete contra suelos rurales en ocasiones no aptos para ser habitados. Espacio público y equipamientos colectivos precarios, y en ocasiones insuficientes o mal administrados coaccionan múltiples problemáticas sociales (Moreno y Rubiano, 2014).

Por otro lado, en las periferias también se ubican suburbios planificados, que cuentan con todos los servicios y equipamientos requeridos, conformando, en la mayoría de casos, fragmentaciones urbanas y sociales de grupos con mayor poder adquisitivo. Por su estratégica ubicación, jalonan de manera ilógica el crecimiento urbano hacia áreas rurales, en ocasiones de especial connotación y valor agrícola. Dichos desarrollos generan dependencia vehicular, y a veces, barrios cerrados; el espacio público se conforma por calles solitarias y muros de cerramiento vistos en la mayoría de ciudades (Borsdorf, Hidalgo, y Vidal-Koppmann, 2016). Si las periferias urbanas son espacios heterogéneos y fragmentados también lo son las zonas rurales aledañas. En ambos espacios, compiten por el suelo grandes terratenientes, promotores, grupos de alta renta, pobladores de bajos recursos, y campesinos. Una competencia asimétrica, generalmente bajo marcos regulatorios permisivos frente a la especulación inmobiliaria. Compiten por el territorio, por el espacio físico, y también 
motivados por imaginarios colectivos sobre lo que es o representa 'lo urbano' y 'lo rural'; imaginarios de prestigio o estigmatización social, y de naturaleza por preservar. En este sentido, el borde es un espacio 'en movimiento'; los bordes de ayer son barrios consolidados de hoy. Esta cuestión del carácter temporal o definitivo del borde es central. ¿La ciudad va a seguir creciendo indefinidamente?

De ahí que, los bordes son la conjunción de situaciones políticas, económicas y socio-culturales. Por lo mismo, invisibles y aparentes discontinuidades, inconformidades y expectantes situaciones son indolentes a la especulación. Surge una dimensión que involucra lo urbano, creciente e invasor hacia lo rural, expectante de ser ocupado: el paisaje intermedio, que es un espacio en transición entre ese paso desde lo ocupado (urbano), que sobrepasa bordes, límites virtuales, y se ubica en lo vacío (rural); es parte funcional de la expansión y del acontecer urbano. "Forma parte de un engranaje que dentro de lo obvio, debe propiciar estrategias y consolidar nuevas necesidades de aquello que lo bordea y limita. Propicia la estructura de nuevos usos y formas como parte de la incorporación de suelo útil" (Neu, 2016, p.57). Sin embargo, prevalecen enfoques unidireccionales 'de lo urbano a lo rural' en la mayoría de estudios, políticas y proyectos sobre territorios de borde (Matijasevic y Ruiz, 2013). La creciente conurbación urbana, suburbanización o post-metropolización exigen un mayor entendimiento del complejo encuentro o desencuentro entre lo urbano y lo rural; adicionalmente, exhorta a entender las especificidades y complementariedades territoriales, sociales, económicas y culturales, los intereses e imaginarios asociados (Alfonso, 2010, Soja, 2000, Rosales, Brenner, y Mendoza, 2012).

Con el ánimo de pasar de la confrontación a la integración urbano-rural, este ensayo explora interpretaciones y enfoques sobre lo urbano, lo rural, y caminos hacia el adecuado manejo del borde urbano y paisaje intermedio, los cuales deben mantener la escala (de los proyectos) y la dimensionalidad (del crecimiento) para zurcir de manera continua el tejido urbano, rural y socio-cultural, y mantener la coherencia con el desarrollo territorial y la sostenibilidad ambiental. 


\section{De lo rural a lo urbano}

L'image peut enfin avoir une valeur de manifeste, se situer dans un courant de pensée ou dans le champ d'une discipline, qu'il s'agisse d'histoire, de géographie, d'architecture ou de tout autre approche des paysages.

Philippe Nys, Introduction aux approches multidisciplinaires des paysages

La territorialidad es la subjetivación de las naturalezas, es el fruto de las interrelaciones entre seres visibles y sutiles.

Patricia Vargas, Historia de Territorialidades en Colombia

La visión del desarrollo se asocia desde lo urbano a términos de localización, producción, rentabilidad, demografía y empleo. La distinción confusa surge cuando se mira la ruralidad con similares preceptos falseando realidades, sin definirla ni centrarla en sí misma. La errada expectativa es transformar lo rural en urbano. La ruralidad, y en especial el borde rural, se considera un territorio vasto, penetrable, fluido y próximo a áreas urbanas, donde la visión político-administrativa incluye estos territorios en un régimen urbano (paisaje natural transformado; paisaje cultural) en cuanto a las necesidades y articulaciones posibles para su desarrollo y usufructo. También se considera como aquel territorio (paisaje natural) del cual se obtienen recursos naturales y se explotan servicios indiscriminadamente (minería y turismo depredador entre otros) (Gómez y Londoño, 2011, Vargas, 2016, Carta, 2017).

Históricamente, lo rural se ha definido en contraposición con lo urbano, desde una perspectiva dicotómica; lo urbano, se asocia al progreso y la modernidad, mientras que lo rural es agrario, atrasado, pobre, residual (Matijasevic y Ruiz, 2013). Se menciona generalmente para delimitar un espacio físico, referirse a un modo de vida, o a la producción agropecuaria. La mayoría de definiciones oficiales se basan en criterios demográficos y político-administrativos (Cuadro 1). Rara vez se mencionan las dinámicas propias de los territorios rurales o las necesidades de sus habitantes.

Estas aproximaciones denotan razonamientos específicos y no integrales pese a que la visión teórica invita a que "la economía rural debe ser considerada como una economía territorial, facilitando una 
comprensión integral y articulada de sus componentes" (Echeverri, 2011, p.15).

Cuadro 1. Criterios para clasificar localidades urbanas y rurales

\begin{tabular}{|c|c|c|c|c|c|}
\hline Criterio & Numérico & Equipamiento & Funcional & Político administrativo & Paisajistico \\
\hline \multirow{4}{*}{ Numérico } & Argentina (1950-1990) & & & Nicaragua $(1960,1970$ y 1990$)$ & \\
\hline & $\begin{array}{l}\text { Bolivia (Estado Plurinacional } \\
\text { de) (1976 y 1992) }\end{array}$ & & & Perú (1950-1990) & \\
\hline & México (1950-1990) & & & & \\
\hline & $\begin{array}{l}\text { Venezuela (República } \\
\text { Bolivariana de) (1950-1990) }\end{array}$ & & & & \\
\hline \multirow{6}{*}{ Equipamiento } & Cuba $(1970$ y 1980$)$ & & & Uruguay (1960-1990) & \\
\hline & Honduras $(1960,1970$ y 1980$)$ & & & Paraguay (1960) & \\
\hline & Panamá (1950-1990) & & & Chile (1950) & \\
\hline & Chile (1980 y 1990) & & & $\begin{array}{l}\text { Costa Rica }(1950,1960,1970 \text { y } \\
1980)\end{array}$ & \\
\hline & Cuba (1950) & & & Nicaragua $(1960,1970$ y 1990$)$ & \\
\hline & Guatemala (1950) & & & Perú (1960) & \\
\hline \multirow[t]{3}{*}{ Funcional } & Chile (1990) & $\begin{array}{l}\text { Chile }(1960 \text { y } \\
1970)\end{array}$ & & Chile (1950) & \\
\hline & Cuba (1950) & & & Nicaragua $(1960,1970$ y 1990$)$ & \\
\hline & Colombia (1960 y 1970) & Costa Rica & & Brasil (1950-1990) & \\
\hline \multirow{9}{*}{$\begin{array}{l}\text { Político- } \\
\text { administrativo }\end{array}$} & & & & Colombia $(1950,1980$ y 1990$)$ & \\
\hline & & & & Ecuador $(1950-1990)$ & \\
\hline & & & & El Salvador (1950-1990) & \\
\hline & & & & Guatemala (1960-1990) & \\
\hline & & & & Haití (1970 y 1980) & \\
\hline & & & & Honduras (1950) & \\
\hline & & & & Nicaragua $(1950)$ & \\
\hline & & & & $\begin{array}{l}\text { Paraguay }(1950,1970,1980 \text { y } \\
1990)\end{array}$ & \\
\hline & & & & $\begin{array}{l}\text { República Dominicana (1950- } \\
\text { 1990) }\end{array}$ & \\
\hline \multirow{2}{*}{ Paisajístico } & Chile (1980) & Chile (1960) & & Costa Rica (1980) & \\
\hline & & & & Perú $(1950,1970,1980,1990)$ & \\
\hline
\end{tabular}

Fuente: CEPAL /CELADE (Centro Latinoamericano y del Caribe de Demografía, 2011)

Como se evidencia en el cuadro 1, numerosos países adoptan criterios numéricos o demográficos para definir zonas rurales mediante umbrales de población. Sin embargo, los límites poblacionales varían de manera significativa de un país a otro, reflejando concepciones concretas y dificultando el entendimiento de lo rural a nivel internacional y regional. 
Cuadro 2. Límites poblacionales en la definición de rural

\begin{tabular}{cl}
\hline $\begin{array}{l}\text { Limite } \\
\text { Poblacional }\end{array}$ & \multicolumn{1}{c}{ Paises } \\
\hline 200 & Dinamarca, Islandia, Noruega \\
400 & Albania \\
500 & Cuba \\
1000 & Canadá, Chile, Nicaragua, Nueva Zelanda, Suecia \\
1500 & Guinea, Irlanda, Panamá \\
2000 & Argentina, Bolivia, España, Estonia, Etiopia, Francia, Guatemala, Honduras, Israel, Liberia, \\
2500 & Paises Bajos, República Checa, Vietnam \\
3000 & Barhain, Estados Unidos, Guam, México, Puerto Rico, Samoa Americana, Venezuela \\
5000 & Lituania \\
10000 & Austria, Botswana, Eslovaquia, India, Sudán, Zambia \\
30000 & Gucia, Hungria, Portugal, Senegal, Suiza \\
50000 & Japón \\
\hline
\end{tabular}

Fuente: CEPAL (2011)

En Colombia, el Departamento Administrativo Nacional de Estadística (DANE) asocia la zona rural al área "resto"; se considera rural a la población que vive por fuera del perímetro de las cabeceras municipales. Con el ánimo de superar las limitaciones evidentes de esta definición, el Departamento Nacional de Planeación (DNP) y la Misión para la Transformación del Campo (2014) propusieron una nueva clasificación del territorio nacional a partir de tres criterios: la ruralidad dentro del Sistema de Ciudades; la densidad poblacional; y, la relación de población urbano-rural. Como resultado, establecieron cuatro categorías de ruralidad: ciudades y aglomeraciones; intermedios; rural; y rural disperso, las cuales intentan mejorar la comprensión de territorios diferenciados y la formulación de políticas públicas adecuadas (Cuadro 3). A pesar de estos intentos, lo rural se sigue definiendo desde afuera y arriba, como un espacio que las ciudades necesitan para a la vez expandirse y subsistir; y el borde como un espacio por invadir y un espacio natural por proteger y/o explotar (para recreación, seguridad hídrica y alimentaria).

Los cambios espaciales, demográficos, económicos y tecnológicos a nivel local y global hoy cuestionan estas perspectivas reductoras (Borja y Castells, 1997). Desarrollo y explotación se han convertido en denominadores comunes que atentan contra el medio ambiente y la sostenibilidad en zonas rurales y franjas urbanas, y no dan cabida a una respuesta endógena de la ruralidad misma. 
Cuadro 3. Propuesta de categorías de ruralidad en Colombia

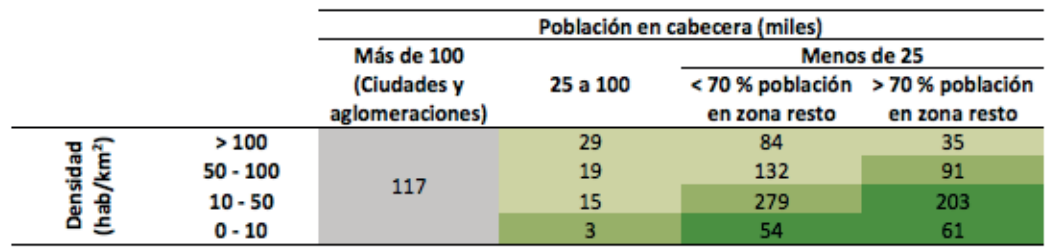

\author{
Ciudades y aglomeraciones \\ Intermedios \\ Rural \\ Rural disperso
}

Fuente: Misión para la Transformación del Campo (2014).

Se transforman los patrones de ocupación espacial, de comportamiento social, y de producción agrícola. Lo anterior, conlleva al abandono, lucha de tierras, agricultura productivista y la consabida migración hacia centros urbanos, variables que no se corrigen, sino que aumentan pese a que se establecen teorías, estrategias y formas de mitigar estas degradaciones (Rosales, 2007). Como resultado, surgen espacios de hibridación urbano-rural ubicados en las periferias de las ciudades grandes e intermedias, en poblaciones pequeñas y en especial en periferias urbano-rurales, consolidadas bajo patrones de desarrollo urbano-industrial. Se convierten en zonas de transición socio-espacial donde confluyen disímiles tipos de hábitat que caracterizan la forma de cómo lo urbano penetra y permea lo rural indiscriminadamente (Pillet, Cañizares, y Ruiz, 2010). Estos diferentes tipos de bordes, que en su mayoría carecen de una estructura espacial funcional, fluyen hacia el paisaje intermedio. Efectivamente, existen bordes entre el límite de lo urbano con lo rural; y también, inmersos dentro de la ciudad conformando vacíos o intersticios, ya sea porque son extensiones que aún no se desarrollan, o porque forman parte de bosques, parques o estructuras ecológicas mayores como ríos, humedales o zonas de mitigación. Montañas y bosques forman un paisaje natural cuyas connotaciones para la sostenibilidad general de los territorios, sus recursos hídricos, y de fauna y flora son indispensables (Martin-Barbero, 2000, Pillet, Cañizares, y Ruiz, 2010).

Desde la perspectiva ambiental, el catedrático Miguel Panadero Moya en un artículo denominado "Geografía humana y sostenibilidad" pertinentemente aborda los términos "sostenibilidad" y "sustentabili- 
dad" como parte del proceso de preservar, proteger y desarrollar las apropiaciones espaciales desde el ámbito del medio ambiente. Una primera aclaración que sugiere el autor citado es que "sostenibilidad" proviene del verbo sostener y "sustentabilidad" de sustentar, entendiendo que "la sostenibilidad se podría lograr con acciones decididas desde afuera, la sustentabilidad requiere que las acciones se decidan desde adentro, en forma autónoma" (2010, p.59).

Por otra parte, en las últimas décadas, los intentos de la sociología rural permitieron captar solo parcialmente la complejidad rural y las crecientes interrelaciones urbano-rurales. El concepto de continuum urbano-rural suplantó progresivamente las definiciones dicotómicas, para referirse a zonas intermedias que no eran ni urbanas ni rurales (Rodríguez y Salas, 2004, Carta, 2017). Autores como Garayo, adoptaron la noción de fusión urbano-rural para resaltar los flujos de población no solamente en dirección rural-urbano sino también urbano-rural, característicos de la sociedad post-industrial (1996), y de una revalorización de la vida rural (modo de vida 'verde', auge de viviendas secundarias campestres, ecoturismo). Se hablaba tanto de urbanización de la vida rural como de ruralización de la vida urbana (Martín-Barbero, 2000).

Al respecto, es diciente la observación de García Canclini: "ciudades africanas, asiáticas y latinoamericanas invadidas por el campo, donde grupos familiares circulando aún en carros con caballos, usos de calles que parecen propios de campesinos, como si nunca fuera a pasar un coche, es decir, intersecciones entre lo rural y lo urbano que no pueden comprenderse en términos de simple oposición" (Garcia Canclini, 1997, p. 5 citado en Matijasevic y Ruiz, 2013). De igual manera, desde los años noventa, se engloba bajo el término nueva ruralidad una serie de estudios rurales que buscan captar la mayor fluidez rural-urbana, la creciente formación de espacios peri-urbanos y la pluriactividad que allí se desarrolla (Pérez E., 2004, Kay, 2007).

No obstante, hacen falta nuevas miradas y abordajes al tercer paisaje de Clément, área "que se expulsa de otros paisajes" (Mozas, 2011:9) y que queda expectante de los desarrollos urbanos futuros o rur-urbanos (Carta, 2017), término que condensa esta problemática del paisaje intermedio. Es lo que se acerca al borde urbano; es aquello que en ocasiones queda desapercibido pero que en realidad produce fragmentación, segregación y una discontinuidad con aque- 
llo que viene desde la mancha de aceite urbana, amorfa e invasiva. Esta situación también resulta de una falta de contextualización e implementación de manejos de sostenibilidad y sustentabilidad acordes a las realidades y necesidades urbano-rurales "abajo-arriba", donde se ofrezcan alternativas compatibles con las formas del habitar local (Rosales, Brenner, y Mendoza, , 2012).

\section{El borde y el paisaje intermedio en Bogotá}

El problema es la falta de una estructura del urbanismo del paisaje. David Gouverneur

En Colombia, los Planes de Ordenamiento Territorial (POT) constituyen la principal herramienta para preestablecer, establecer y proyectar el adecuado uso de los territorios a corto, mediano y largo plazo. Sin embargo, la extensa bibliografía y teorización sobre los POT y su problemática implementación revela que impera un ordenamiento territorial jurídico jerárquico más que de gestión (DNP, 2010, Velázquez, 2010). La implementación de muchos POT y sus derivaciones quedan impresas en extensos documentos amparados en leyes y procesos, que se alejan de gestiones y manejos de participación ciudadana (abajo-arriba), prevaleciendo el Estado-patrón (arriba-abajo) (Matijasevic y Ruiz, 2013). Prevalecen intereses particulares que son visionarios de procesos especulativos y fragmentarios del territorio. Velázquez manifiesta esto de manera explícita donde el "enfoque de la planeación, que establecía una clara distinción entre técnica y política, entre el carácter de la planificación y el para qué de la misma, perdió credibilidad por su fracaso como propuesta de cambio controlado (social, económico, territorial, organizacional) y por la crisis de los paradigmas teóricos que la sustentaron durante varias décadas (concepción positivista del universo como un orden dado, sometido a regularidades universales y, por tanto, predictible)" (2010, p.12). Adicionalmente, la baja coordinación interinstitucional, acentuada en temas y territorios que no son propiamente urbanos ni rurales, impide anticipar, regular y orientar las dinámicas territoriales en dichos espacios de borde.

En consecuencia, se observan nuevas fragmentaciones en circunscripciones rurales cercanas por ejemplo a Bogotá, donde el crecimiento amorfo propicia ya sea el suburbio formal (conjuntos de vivienda detrás de rejas) o barrios informales, jalonando un crecimien- 
to inesperado que en general afecta negativamente el medio ambiente y la actividad urbana. Diversos casos aparecen en la geografía contextual de poblaciones rur-urbanas dormitorio, cuya economía local mínima basada en servicios primarios, crea dependencia hacia centros urbanos mayores, generando problemas de conectividad y la subordinación hacia empleo y actividades productivas mal remuneradas. Así es como surge un nuevo tipo de segregación socio-espacial desde realidades que aumentan el distanciamiento social debido a los precarios servicios de transporte público, a los largos viajes que se recorren desde los lugares de habitación hasta los lugares de trabajo, con el consecuente deterioro de la calidad de vida de las personas (Moreno y Rubiano, 2014). Un caso es el de Puente de Piedra, a escasos 25 km de Bogotá (Alcaldía Municipal de Madrid Cundinamarca, 2008). El poblado se ha ido consolidando de manera irregular a lo largo de la autopista a Medellín y las carreteras que conducen a las poblaciones de Subachoque y Madrid (Imagen 1 y 2). El crecimiento urbano fragmentado e irregular denota la carencia de planeación y control del crecimiento, generando una discontinuidad urbana, causando vacíos, desarticulando posibles centralidades y dejando un problema patente sobre la provisión adecuada de servicios públicos, equipamientos y espacio público. Intersticios vacíos renuncian a un ordenamiento y permean el imaginario de un crecimiento irregular futuro.

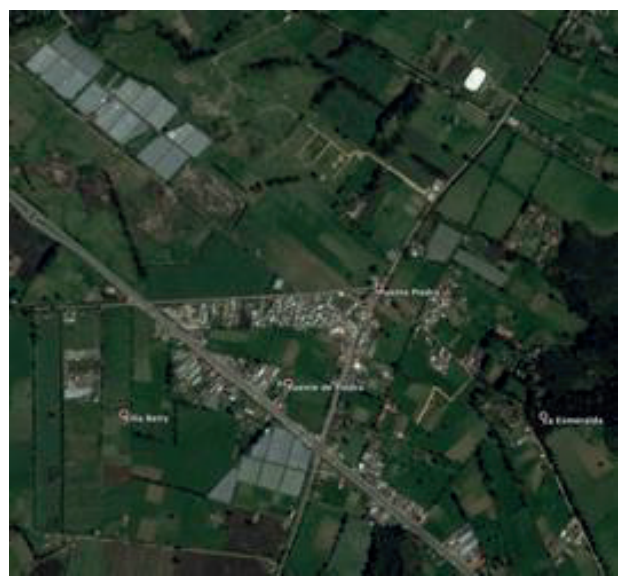

Imagen 1. Informalidad incipiente - Zona ampliada de Puente de Piedra, Cund. Fuente GoogleEarthPro. 


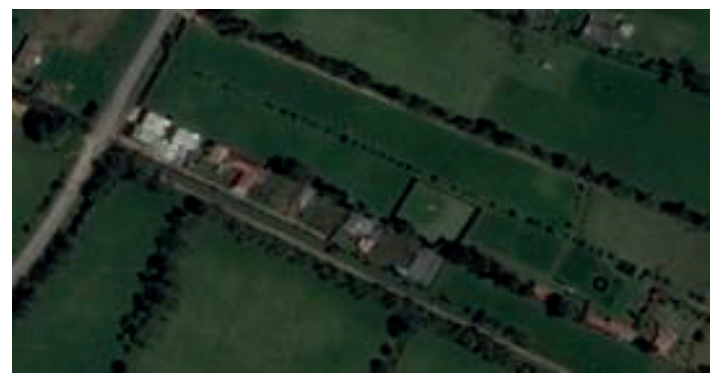

Imagen 2. Informalidad disfrazada e incipiente - Puente de Piedra, Cund. Fuente Googlemaps.

La oferta de lotes y vivienda de bajo costo con la promesa de servicios, acogen a incautos dentro de una informalidad disfrazada e incipiente. Lo que hoy se perfila genera una tipología de barrio aislado bordeado por fincas y zonas agrícolas o lo que hemos denominado un urbanismo híbrido fragmentado. Deficientes o inexistentes redes de acueducto y alcantarillado en estas zonas rur-urbanas presentan hoy en día grandes cuestionamientos acerca de la idoneidad de los POT, los controles, la gestión y la posibilidad de conformar un hábitat sostenible y adecuado.

Por otro lado, el surgimiento de loteos urbanos de alta densidad de vivienda básica que imponen pre-consolidaciones urbanas, también participan de la negación reiterada sobre la continuidad urbana y consolidación de poblados dentro de unos bordes definidos, cuestionando las opciones físico-espaciales que estos poblados tendrán a futuro.

Históricamente, la informalidad de muchos barrios en Colombia había propiciado la continuidad del damero como elemento urbano organizador, comparado con favelas o barriadas en otros países. La irregularidad siempre ofrecía la opción de vías vehiculares, el futuro parque y una estructura que a la postre sería 'fácil' de incluir en el sistema y tejido urbano imperante de la ciudad formal. Sin embargo, lo que se ve replicado en diversas poblaciones de la Sabana de Bogotá son loteos de parcelas subdivididas en una multiplicidad de lotes pequeños más allá de las fronteras urbanas; conjuntos cerrados con mínimos aislamientos; y el cumplimiento de mínimos en vías de penetración, como fragmentos definen un todo caótico y discontinuo. 
En síntesis, los barrios o conjuntos de vivienda así conformados tejen una red de conexiones incompletas, que en todo caso logra conformar un germen de lugar con una narrativa distinta a la que ocurre con el ordenamiento y planificación de entornos urbanos adecuados, implicando un proceso de sprawl invasivo hacia lo rural. Un jalonamiento urbano informal que a futuro traerá problemáticas derivadas de la falta de políticas urbanas y de planificación que manejen el territorio de manera holística; problemas de sostenibilidad (desde afuera) y sustentabilidad (desde adentro). Al salir de estos enclaves rur-urbanos hacia los centros urbanos mayores, emergen en las periferias densos asentamientos informales, bajo una óptica de tolerancia y un vaho de indulgencia. Se ubican en suelos que son aprovechados y sujetos a la creciente demanda habitacional insatisfecha amarrada al déficit de vivienda formal (Moreno y Peña, 2004). Así vista, la ciudad "en su manifestación da la apariencia de no ser una sino múltiple" (Giraldo, 1999, p. 69) que actúa como núcleo social fragmentado, segregado y abandonado por la institucionalidad.

Tal vez, uno de los casos más analizados de la problemática de la urbanización informal y la necesidad de resolver demandas sociales incrementales es la del municipio de Soacha en cercanías de Bogotá (Moreno A. , 2009, Moreno y Peña, 2004, Moreno y Rubiano, 2014, Dávila y Brand, 2012). Presenta una conurbación clara, definida y real con Bogotá, pero carece de un sistema de gobernabilidad y gobernanza metropolitana capaz de enfrentar problemáticas territoriales en una geografía que sobrepasa los límites político-administrativos establecidos. La funcionalidad urbana de esta población se basa en la informalidad. Ésta ha sido la manera de consolidación de este territorio desde los años 1950 debido a bajos controles, costos del suelo asequibles, mano de obra no calificada requerida por la industria de extracción minera local, y la dependencia económica hacia Bogotá (Moreno y Peña, 2004, Dávila y Brand, 2012). Desde entonces, su borde se amplia, a la par con ensayos oficiales de controlar el crecimiento amorfo con intervenciones formales público-privadas que incentivan aún más la invasión y el desarrollo espontáneo de urbanizaciones (Moreno y Peña, 2004). Paradójicamente, censos recientes muestran que Soacha cuenta con altas coberturas en servicios domiciliarios (DANE, 2003, 2010).

En cercanías, desarrollos como los de Ciudad Bolívar, Usme y Bosa (Bogotá) en terrenos agrológicos no aptos para vivienda estimulan la 
invasión de las laderas del sur de la capital y zonas rurales contiguas, desplazando los bordes sur-orientales y sur-occidentales sin ningún control. La conurbación y consecuente pérdida de un límite claro, en zonas escarpadas, densas y alejadas de administraciones indolentes con la informalidad es evidente. Dichas dinámicas territoriales en bordes urbanos y zonas rurales aledañas, esencialmente ligadas a la búsqueda de una vivienda 'posible', conllevan múltiples efectos negativos asociados a la segregación socio-espacial, la movilidad deficiente, y los altos costos de infraestructura frente a reducidos ingresos municipales por concepto de impuesto predial y transacciones de compra-venta (en desarrollos informales) (Moreno y Peña, 2004; UN-Habitat, 2016).

Los impactos ambientales producto de la ocupación de áreas de reserva y/o riesgo, como la disminución y contaminación de fuentes hídricas, son particularmente preocupantes. Se manifiestan en diferentes escalas al atentar contra la Estructura Ecológica Principal (EEP) de territorios urbanos y rurales interconectados. La Secretaria

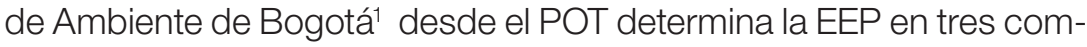
ponentes definidos a continuación:

- El Sistema de Áreas Protegidas Distritales: es el conjunto de espacios con valores singulares para el patrimonio natural del distrito, la región y la nación, cuya conservación resulta imprescindible para el funcionamiento de los ecosistemas, la conservación de la biodiversidad y la evolución de la cultura en el distrito. Todos sus elementos son suelo de protección.

- Los parques, en la categoría de parques metropolitanos y urbanos, que agrupan aquellos elementos del espacio público, destinados a la recreación pública, cuya función principal dentro de la Estructura Ecológica Principal es la de establecer la conexión espacial entre los elementos del sistema de áreas protegidas, dando continuidad a la estructura. Todos sus elementos son suelo de protección.

- El Área de Manejo Especial del Valle Aluvial del Río Bogotá dentro de la cual sólo es suelo de protección, la franja de terreno desde el Puente del Común hasta Alicachín, que incluye la

1 http://www.ambientebogota.gov.co/c/journal/view_article_content?groupl$d=10157 \&$ articleld=14190\&version=1.2 Con acceso julio 16, 2017. 
ronda hidráulica y la zona de manejo y preservación ambiental del río, definida con el fin de coordinar las acciones distritales requeridas para potenciar el río como el principal eje de articulación con el contexto regional.

La expansión urbana descontrolada en periferias y bordes urbano-rurales amenaza y fractura la EEP como sistema conectado y proveedor de servicios ambientales indispensables a la vida humana. En el caso de Bogotá, la fragmentación de la EEP ocurre tanto "desde afuera" como acabamos de explicitar, como "desde adentro". Efectivamente, Bogotá cuenta con una riqueza hídrica especial en las estribaciones de los cerros orientales tutelares. Ríos y quebradas otrora bajaban hacia la sabana en busca del río Bogotá, hasta llegar a lagunas, zonas de amortiguación hídrica naturales y humedales. Sin embargo, dichos espacios comenzaron a ser intervenidos y desecados a partir del primer tercio del siglo XX por el afán de urbanizar. Humedales, ríos y quebradas fueron encausados y canalizados. Los cuerpos de agua se redujeron y quedaron en ocasiones aislados y apresados entre canales y urbanizaciones; se convirtieron en muladares y con ello se atentó contra la flora y la fauna que estos enclaves naturales contenían (Empresa de Acueducto y Alcantarillado de Bogotá, 2003). Ante esta degradación de los sistemas hídricos, se desarrollaron programas tendientes a proteger, conservar, pero también desarrollar los cerros tutelares construyendo corredores ecológicos e interviniendo los canales, humedales y lagunas, estableciendo parques lineales extensos dentro de la ciudad (Imagen 3).

En el caso particular de los humedales, se intentó desarrollar modelos bajo el criterio de la conservación y optimización de lo biótico y lo urbano. Casos emblemáticos fueron los humedales Juan Amarillo, Jaboque, y Córdoba en Bogotá (Imagen 4). Apropiados por la población para uso lúdico, y que fueron sistemáticamente olvidados por administraciones públicas, dando cuenta de la degradación, fragilidad e inminente riesgo que reservas acuíferas, de flora y fauna de la ciudad tienen y sufren debido al abandono en su manutención y continua gestión. Reiterando, la mayoría de humedales hoy se encuentran rodeados por la masa urbana consolidada a través de los años, bien sea formal o informal, y aún constituyen enclaves naturales frágiles, desaprovechados y amenazados. 
Imagen 3. Sistema hídrico de Bogotá

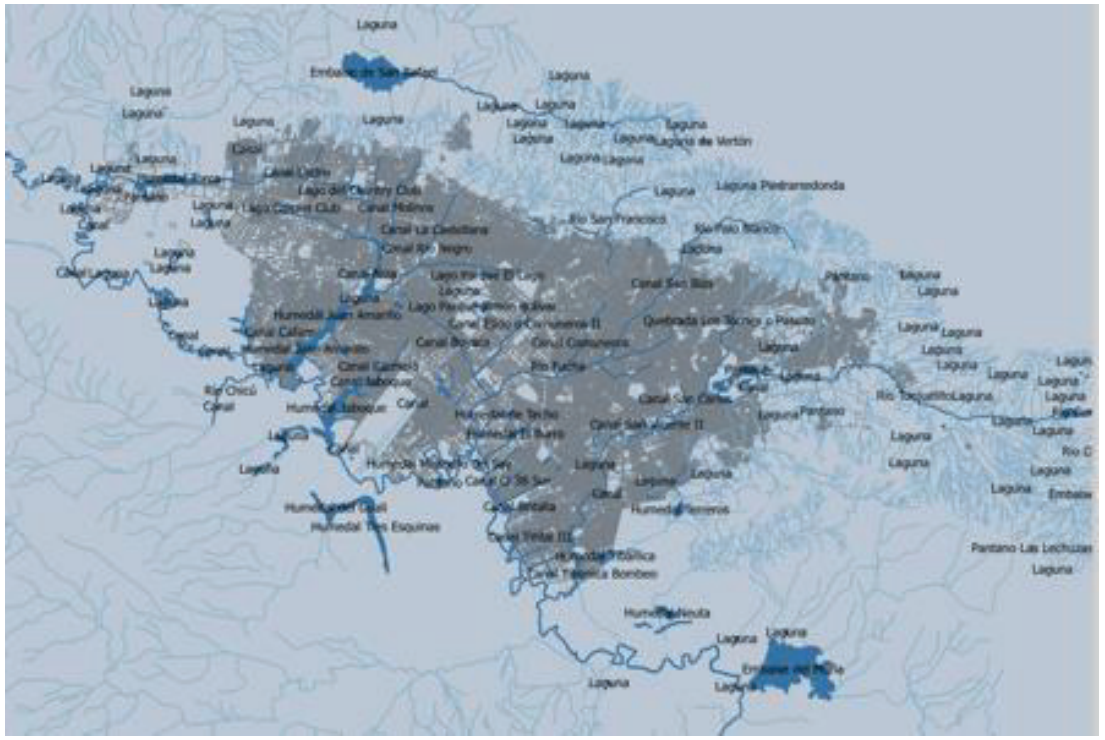

Elaboración propia.

Imagen 4. Parque Juan Amarillo, Bogotá. Recorre la ciudad de oriente a occidente hasta el río Bogotá.

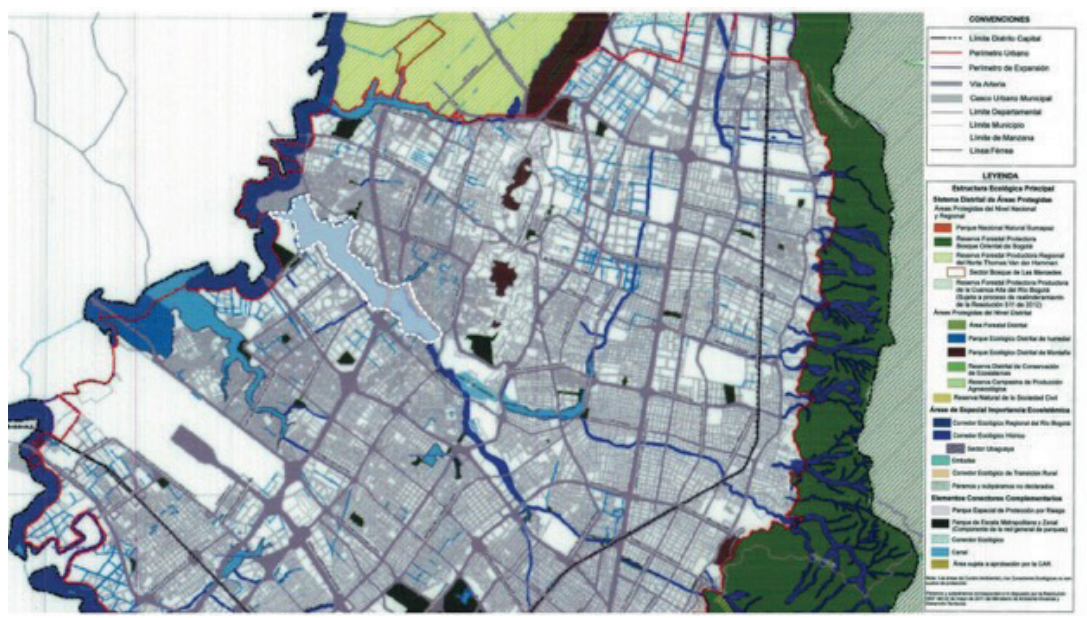

Fuente: Secretaria Distrital de Planeación. (17 de Mayo de 2017). Obtenido de http://www. sdp.gov.co/portal/page/portal/PortalSDP/POT_2020/Cartografia. 
Por lo tanto, es imprescindible aprender de estos intentos y de los resultados positivos logrados sobre el manejo de bordes y paisajes intermedios; en el potencial que tienen estos enclaves para fortalecer la sostenibilidad y sustentabilidad a diferentes escalas, y de ofrecer espacios lúdicos y de esparcimiento amplio fortaleciendo a su vez el tejido social. Invitan estos espacios a recuperar los paisajes natural y cultural sometiéndolos a nuevas opciones como son la intervención de soportes basados en ejes, nodos, custodios, intervenciones urbanas (espacio público cotidiano) y arquitecturas claras que ayuden a la consolidación urbana, y a definir el paisaje natural como parte integral de lo urbano (Stephenson, 2002; Thompson, 2014; Gouverneur, 2016; Neu, 2016).

Imagen 5. Corredor Ecológico y Recreativo del borde oriental de Bogotá.

Propuesta Barrio las Violetas..

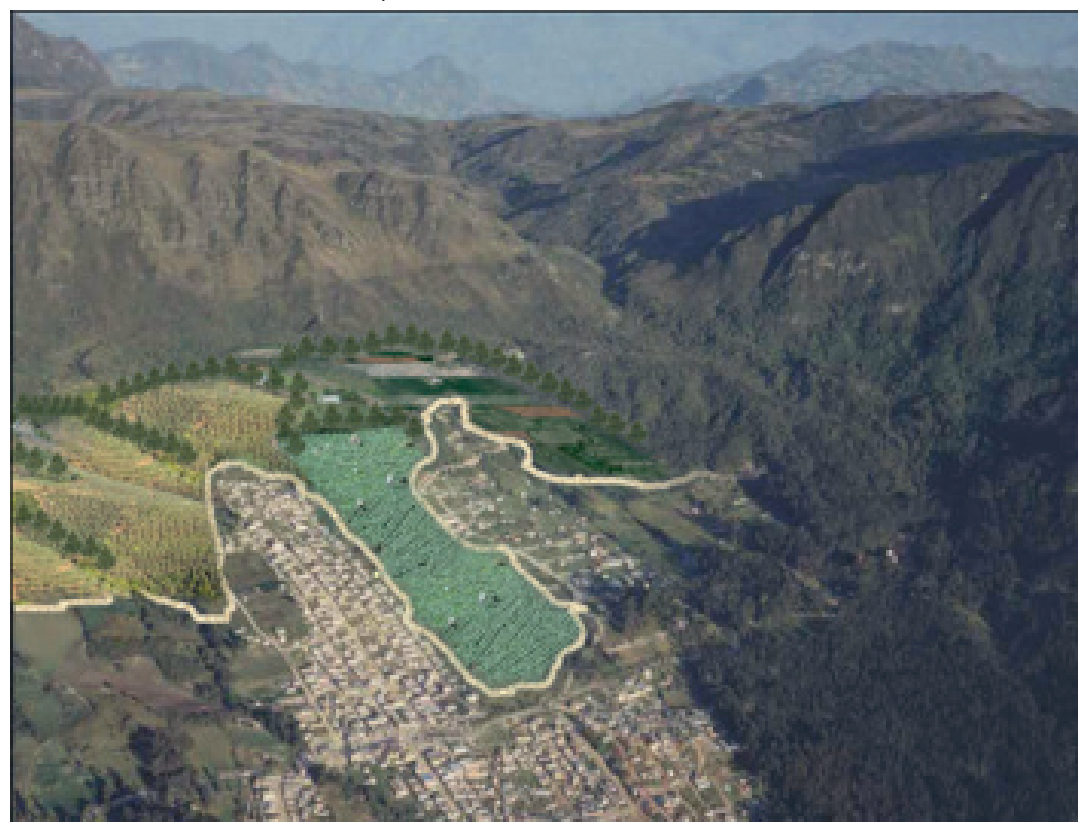

Imagen cedida por Diana Wiesner - Arquitectura y Paisaje EU.

A manera de ilustración, la experticia de la arquitecta paisajista Diana Wiesner Ceballos, en su propuesta para el Corredor Ecológico y Recreativo del borde oriental de la ciudad en el barrio Las Violetas (localidad de Usme, Bogotá), plantea un área continua, conectada y 
articuladora (social y ecológicamente) que demarca el límite de la ciudad y se integra a la red de eco-rutas y caminos existentes de forma permeable al tejido urbano y a la reserva forestal oriental. Dicha área constituye una estrategia de pacto de borde con vecinos y actores territoriales (Imagen 5). ${ }^{2}$

\section{Nuevas miradas multidisciplinarias}

El concepto de espacio socialmente construido enmarca perfectamente
con una visión más compleja de las interrelaciones que existen entre el
territorio, el mundo productivo y socio-cultural. Rocío Rosales Ortega

Plantear una dialéctica de 'lo rural a lo urbano' (intereses, expectativas, temores, cuestión del beneficio general frente a la protección de entornos naturales), y aquello que tiende 'de lo urbano a lo rural' o 'de la expansión urbana' define el borde urbano, realza la vulnerabilidad del paisaje intermedio y puntualiza una problemática específica sobre el manejo del territorio: sobre su desarrollo, sostenibilidad y sustentabilidad ambiental. Surge la inquietud de 'con cuáles ojos se mira' esta hibridación, ya que su conceptualización impacta nuestra lectura de la realidad socio-espacial sobre las formas en las que la medimos, los resultados obtenidos, y por ende como se optimiza el diseño de políticas públicas para una adecuada gestión.

Más de veinte años atrás, la antropóloga Luz Nereida Pérez advertía: "los cambios culturales en las estructuras sociales vía la migración, así como los patrones de inversión y las políticas estatales que interactúan con las actividades de los actores sociales en cada espacio geográfico y generan cambio social, requieren enfoques que capturen el entrejuego entre: 1) la política y la economía, 2) el Estado y la sociedad, 3) los actores sociales y las estructuras, y 4) la comunidad, la cultura y las identidades" (1993, p. 15). Frente a las limitaciones y sesgos, anteriormente mencionados, enfoques multidisciplinarios alternativos abren nuevas perspectivas en el entendimiento de las complejas interrelaciones urbano-rurales en espacios de borde. Dichos abordajes conceptualizan lo urbano y lo rural como una construcción social y prefieren la categoría territorio, que cristaliza la relación del hombre con el espacio (Matijasevic y Ruiz, 2013, Rosales,

2 Conversaciones con Diana Wiesner. En: www.dianawiesner.com, con acceso agosto 12, 2017. 
2007, Rosales, Brenner, y Mendoza, 2012, Vargas, 2016). Invitan a abordar, desde aproximaciones transversales y gobernanzas enfocadas en el desarrollo local y territorial integrado, el abanico de recursos tangibles (lo construido, lo natural) e intangibles (tradiciones, cultura), bases antropocéntricas del ser (Lozano, 2007).

Vale la pena insistir en que las transformaciones territoriales, objeto de este artículo, se basan en una serie de interrelaciones entre condiciones geográficas, ambientales y demográficas, sistemas de gobernabilidad y gobernanza territorial, relaciones político-económicas en torno a usos potenciales del suelo (urbano vs rural, industrial), aspectos legales y normativos, variados patrones de ocupación y tipologías de vivienda, redes y servicios necesarias y/o requeridas (infraestructura vial y de servicios públicos, equipamientos, espacio público), prácticas socio-culturales, identidades e imaginarios, entre otros. Por lo tanto, es necesario fortalecer aproximaciones holísticas y sistémicas de bordes urbanos que conjuguen dinámicas sociales, económicas, territoriales, ambientales, políticas y culturales fundamentadas en el desarrollo como un proceso incluyente, regulado, sostenido y sustentable (Cuesta, 2013). La aproximación sistémica sugiere enfoques de tipo conceptual y práctico que permiten explorar realidades múltiples y tomar decisiones desde la confluencia de disciplinas, escalas de análisis e intervención, y la reducción de sesgos sectoriales, dando especial significado al hecho de la preservación, transformación y armonización del territorio. Bien lo dice Alejandro Angulo Novoa en el prólogo del libro de Patricia Vargas Sarmiento que "esta preocupación ecológica se basa en la visión biocéntrica, para la cual, todos los seres vivos y su ambiente conforman un todo inseparable y tienden hacia un equilibrio en sus respectivas interacciones" (2016:26). Deben ser ires-venires-ires que se cruzan, entrelazan y entretejen dentro de lo material e inmaterial de tradiciones vivas urbanas y campesinas que persisten en estos espacios híbridos (Rosales, Brenner, y Mendoza, 2012; Rosales, 2007).

De manera privilegiada, compete a la conjunción disciplinar denominada urbanismo del paisaje, que integra el paisaje natural con la planeación territorial y el diseño urbano, parte de las respuestas demandadas. Se valora desde el paisaje la integralidad del contexto y se hace más consciente el trabajo de generar calidad de vida y preservar el medio ambiente involucrando sistemas de sostenibilidad y sustentabilidad (Gómez y Londoño, 2011; Thompson, 2014). Este 
enfoque concibe el territorio como un componente conformado por diversos espacios y procesos que deben configurar y dirigir límites y bordes dentro de un sistema complejo para lograr armonía (Batty y Longley, 1994; Luhmann, 1996; Rendón, 2009). En otras palabras, son los diversos paisajes que componen el conjunto del territorio, y el espacio específico donde las actividades habitacionales y productivas se concretan. Abordar la temática de paisajes vivos, su protección, mantenimiento y fortalecimiento como estructuras ecológicas que transitan hacia la preservación del medio ambiente y la consolidación del desarrollo, determina a su vez la relación profunda entre paisaje natural y paisaje cultural identitario (Gómez y Londoño, 2011). Estas concepciones dirigidas "abogan por el uso de la 'infraestructura verde', donde se funden aspectos ambientales, morfológicos, funcionales y culturales" (Gouverneur, 2016:188) de un urbanismo que soporta enclaves diseñados para una sostenibilidad social. Allá donde nuevas realidades son elaboradas desde lo netamente humano hacia lo cultural emanado a partir de la conceptualización del espacio público, de aquella espacialidad cotidiana, donde se podría lograr la adecuada interacción espacial y la actividad urbana (Wolfrum y Frhr. v. Brandis, 2015).

Al respecto, investigadores como Schröder, Carla, Ferretti y Lino (2017) proponen reposicionar nociones de planeación y diseño inherentes al lugar, y a la espacialidad para generar especificidades y marcos estratégicos de desarrollo abordando asentamientos, infraestructura y paisaje natural. Estas cartografías propician una reducción de escala y contextos; una focalización hacia la planificación específica de lo que va quedando como territorio que puede y debe ser intervenido. Trabajar a partir de ahí la ‘urbanización’ del ámbito rural visibiliza una cartografía explícita basada en un territorio delimitado por zonas protegidas (enclaves naturales, enclaves de flora y fauna, zonas hídricas, bosques nativos), zonas rurales con asentamientos humanos (poblados), fincas dispersas productivas, fincas dispersas no productivas, zonas no protegidas, zonas de topografía especial, y un sistema de infraestructura de bienes y servicios fundamental para el desarrollo. La ruralidad determina entonces un territorio vasto cuya importancia biótica como un todo, contiene enclaves que deben ser vistos como manchas de sostenibilidad, y donde la sustentabilidad define estrategias y espacios específicos de desarrollo, con posibilidad de ser transformados. Se entiende que estos espacios son parte 
de un componente mayor, que incluso penetra y permea en áreas urbanas (Gómez y Londoño, 2011).

Es precisamente en los bordes donde el razonamiento entre la importancia y el significado de intervenir el paisaje intermedio, y la iniquidad surgida por lo intra-urbano e inter-urbano debe contenerse hacia lo rur-urbano. Es decir, el paisaje intermedio queda definido como aquella franja que permite que acciones específicas mitiguen los efectos de los modelos fragmentarios y segregacionistas de crecimiento urbano sobre el territorio rural, potencializando su funcionalidad de articulación (Neu, 2016). Esos intersticios pueden "mutar y convertirse en bordes internos de la ciudad, en los que se establece la relación funcional" (Cortés J. M., 2012:130) requerida para la consolidación del paisaje intermedio. Lo anterior, ayuda a enfocar las diversas escalas, a entender las espacialidades que determinan intersticios naturales, híbridos, estructuras ecológicas jerárquicas, y opciones de funcionalidades urbanas, rur-urbanas y rurales de desarrollo. Una urdimbre tejida a partir de lo socio-cultural y del paisaje.

\section{Posibles caminos desde el urbanismo}

A partir del diseño urbano, el urbanismo, y el urbanismo del paisaje, se conceptualizan y concretan objetos arquitectónicos donde la función urbana es capaz de fortalecer comunidades. Bien lo dice Salazar: "la ciudad se construye con profecías, ya que sin ellas no hay esperanzas, y con memoria, ya que sin ésta no hay comunicación" (2016, p.113). Nuestras ciudades latinoamericanas incluyen esperanzas fundadas en la informalidad para forjar un mejor futuro; ese porvenir alude y termina confirmando hechos urbanos más allá de realidades resueltas. La informalidad acoge principios ordenadores insertos en lógicas populares que imprimen una funcionalidad que, más allá de lejanías y periferias, riesgos y entornos, ofrecen opciones de consolidación urbana y establecimiento formal, a través de los equipamientos y servicios otrora faltantes. Esto no quiere decir que la informalidad deba prevalecer o ser consentida, tolerada o aceptarse con desidia. A partir de gestiones y esquemas de gobernanza adecuados, del control y liberación oficial de límites y bordes, la funcionalidad del paisaje intermedio, y la incipiente aparición de servicios, equipamientos, vías y transporte es que deben surgir nuevos enclaves como parte de la rápida consolidación urbana y conectividad rur-urbana (Gouverneur, 2016). 
Imagen 6. Funcionalidad del Paisaje Intermedio y su estructuración a partir de los Soportes Informales.

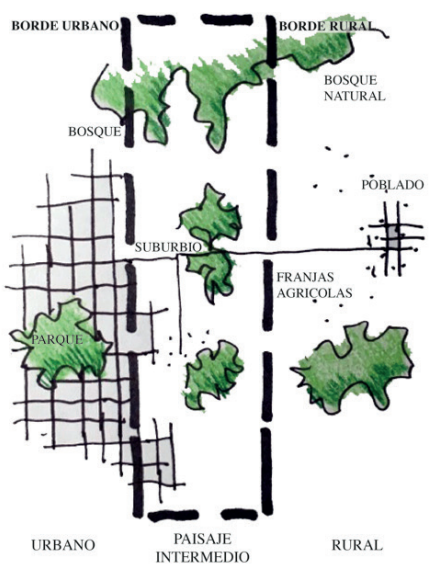

Elaboración propia.

El sistema relacional rur-urbano debe encausar esas necesidades y requerimientos donde equipamientos y servicios tienen un papel preponderante de consolidación, definición, transformación y conservación del paisaje natural, fortaleciendo el hecho de germen de ciudad (Wolfrum y Frhr. v. Brandis, 2015; Gouverneur, 2016). La funcionalidad diacrónica, así vista, es la ecuación necesaria para el diseño, concreción y desarrollo del paisaje intermedio como generador, desde el borde urbano, de un ordenamiento que zurza morfológicamente lo urbano con lo rural. Se define aquí morfología como la forma urbana básica que, en principio, define vialidades y los espacios a ser ocupados por construcciones; también de cómo la formación de ejes, nodos y armaduras se confabulan para generar espacialidades y ofrecer connotaciones de permanencia y pertenencia (Imagen 6) (Gouverneur, 2016; Neu, 2016).

Autores como Escallier (2006) y Carta (2017), desde una perspectiva metabólica de lo rur-urbano, donde lo biótico zurce urdimbres y tramas envolviendo de manera holística el territorio a partir de inteligencias colectivas y el rompimiento de fronteras impuestas, espontáneas e imaginarias, alude hacia un esquema complementado entre sí. Áreas intervenidas, movimientos y cultura deben conformar archipiélagos donde la osmosis social (entendida como la difusión 
social), los conectores urbanos y las interfaces crean identidades y especificidades dentro del territorio (Carta, 2017). Ampliando esta temática, el manejo específico de bordes urbanos, a partir de un exhaustivo diagnóstico e inventario de flora y fauna, permite jerarquizar acciones de tipo socio-espacial con relación a los paisajes natural y cultural. Vale mencionar en ese sentido los parques e intervenciones de arquitectos paisajistas como Frederick Law Olmsted (1822-1903) y Roberto Burle Marx (1909-1994), exponentes de un trabajo que fusiona lo natural y lo transformado en enclaves urbanos que realzan el paisaje natural como parte de sistemas más complejos. También como lo menciona en sus conversaciones la arquitecta paisajista María Altagracia Villalobos, se llega a una metamorfosis histórica donde el nuevo paradigma de vida fundamenta el jardín botánico y el paisaje urbano como una entidad acogiendo lo biótico y consolidando imaginarios sociales.

Resalta en la historia del urbanismo moderno, por otra parte, John Nolen (1869-1937), arquitecto paisajista y planificador norteamericano, quien logró conjugar una ética social en la cual se equilibraban ideales cívicos, naturaleza y responsabilidad pública. El tema de enclaves técnicamente creados y urbanísticamente diseñados (Cortés J. M., 2012) se traduce hoy en día en las pretensiones del Nuevo Urbanismo que se contrapone al suburbio y sprawl norteamericanos (Stephenson, 2002). La adecuada planificación de un territorio supone precisamente inventariar y analizar potencialidades para tomar decisiones en cuanto a protección y conservación ambiental, usos (vivienda, industria) y activos (vías, equipamientos, establecimientos comunitarios, privados, públicos, etc.) para el desarrollo humano (Salom, 2010).

Como se mencionó anteriormente, algunos humedales en Bogotá se encuentran rodeados por la masa urbana consolidada a través de los años. Estos enclaves pueden ser espacios adecuados para esparcimiento y actividades acordes a su conservación, y ofrecen una oportunidad de intervención del paisaje intermedio. Por lo tanto, surten efecto por cuanto cosen sectores urbanos ofreciendo opciones espaciales que valoran este tipo de paisaje unido al espacio público (en sentido amplio), fortalecen las intervenciones y espacialidades de zonas urbanas, y definen el urbanismo del paisaje. Propician lo lúdico, la movilidad en bicicleta, enclaves especiales y logran hacer de las ciudades lugares más amables y con mejor calidad de vida. 
Se garantizan de esta manera estructuras ecológicas que preservan sistemas hídricos jerárquicos y concientizan a la comunidad sobre la necesidad de convivir y proteger el entorno natural. Algunos humedales están rodeados por barrios informales contenidos por frágiles enclaves naturales. Al volver a una escala mayor, donde los procesos formales e informales de urbanización son parte de la dinámica de crecimiento de las ciudades latinoamericanas, la informalidad contiene características socio-culturales y socio-económicas específicas que suplen carencias de lo que la ciudad formal ofrece y a la cual una importante porción de la población no puede acceder. Estos parques lineales que sostienen fuentes hídricas pueden ser parte fundamental de una oferta de espacios verdes y zonas de esparcimiento en las periferias, que se han convertido a lo largo del tiempo en lugares consolidados, activos, y parte integral del contexto.

Surgen de ahí conceptualizaciones para formalizar los desarrollos informales mediante lineamientos de ordenamiento y mejoramiento general de los barrios y ejes que involucran contextualidades urbanas mayores, con el propósito de acompañar y propiciar la consolidación y articulación de estos territorios (Gouverneur, 2016). La falta de calles pavimentadas, aceras, escaleras públicas para vencer escarpados terrenos; equipamientos comunitarios; y condiciones adecuadas de las viviendas, son algunos de los elementos que deben resolverse mediante programas de legalización y mejoramiento de barrios y viviendas, para dinamizar un espacio público vital donde esas viviendas productivas propician la consolidación mencionada. Nuevas tendencias reconocen estas espacialidades y la temporalidad de la vivienda autoconstruida. Gouverneur adopta en ese sentido los Soportes Informales que "pueden asumirse como un enfoque híbrido, en el cual los atributos de los dinámicos entramados sociales de las áreas de crecimiento espontáneo se combinan con visiones planificadas y diseñadas para que resulten sostenibles" (2016:81). Por ello, una aproximación autónoma surge para delimitar bordes urbanos, ojalá desde la ruralidad, definiendo una zona de transición entre lo urbano y lo rural, que se denomina "Paisaje Intermedio" (P.I.) (Neu, 2016). A partir de ese p.i., intervenciones puntuales a diversas escalas, y a partir de variados lenguajes espaciales, se puede controlar el crecimiento urbano desaforado como herramienta que establece complejidades sistémicas de tipo arquitectónico y espacio urbano público, sobre una red y/o sistema de conectividad estructurado, jerárquico y consecuente con esta ocupación semi-urbana/ semi-rural, y aquellas 
apropiaciones que los pobladores mismos puedan incorporar. Dichas intervenciones deben partir del reconocimiento de condicionantes y vocaciones locales, y de las complejas relaciones, prácticas e imaginarios socio-territoriales de los actores públicos, privados y sociales, en el marco de un modelo claro de ordenamiento territorial metropolitano (Imagen 7).

Imagen 7. Sistemas de Soportes, eje, nodos, armaduras. Ubicación de límites y bordes conjunción del paisaje intermedio. Dibujo P. Medina- T. Neu.

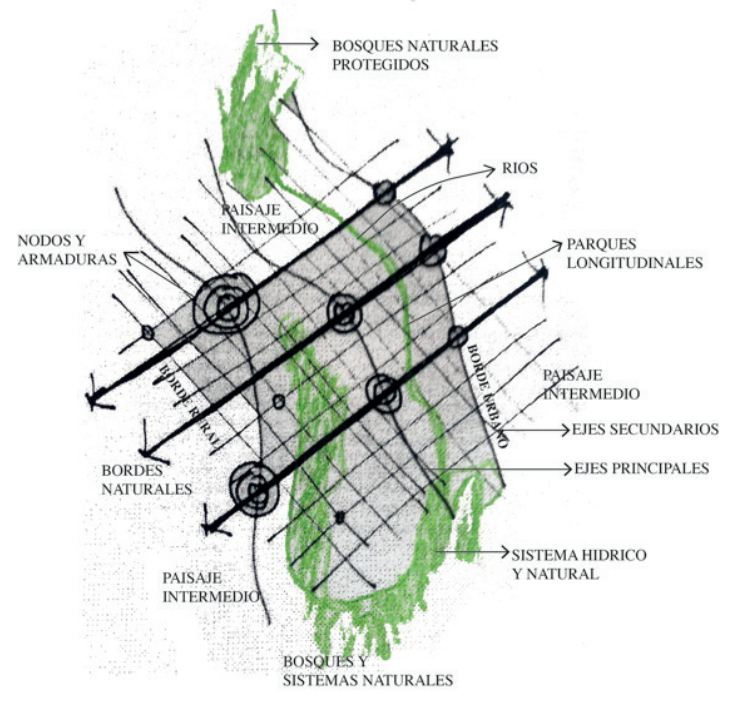

Es necesario recalcar que la masa urbana informal crece sin opciones de una intervención estatal no únicamente en los bordes urbanos de las ciudades sino también en territorios rurales dejando un legado futuro irresoluto en el presente. No se han hecho las tareas de manera consciente. Lo anterior, plantea la necesidad práctica de conjugar desde lo holístico estrategias para acometer lo hasta ahora mencionado. La elaboración de una matriz interpretativa como parte de un estado del arte se propone para tener una cartografía única del territorio que sustente la toma de decisiones (Imagen 8).

Definidos tres tipos de borde: urbano, rural y rur-urbano confinando el paisaje intermedio a las presiones de ser ocupado, se incitan a interactuar entre sí. La conjunción determina actuaciones sobre el territorio amplio rural y sobre la presión que ejerce la ciudad para 
expandirse. Ello define fronteras impuestas, espontáneas e imaginarias sobre la ocupación (Escallier, 2006). Las normas y la formalidad de procesos se enfrentan a lo informal, y a lo requerido y necesario como parte del devenir social y económico de la población. Sustenta lo anterior la intervención sobre los diferentes paisajes y las diversas formas de abordarlos (Pillet, Cañizares, y Ruiz, 2010; Rosales, 2007; Carta, 2017).

Imagen 8.Estrategias para el manejo de bordes desde el Paisaje Intermedio.

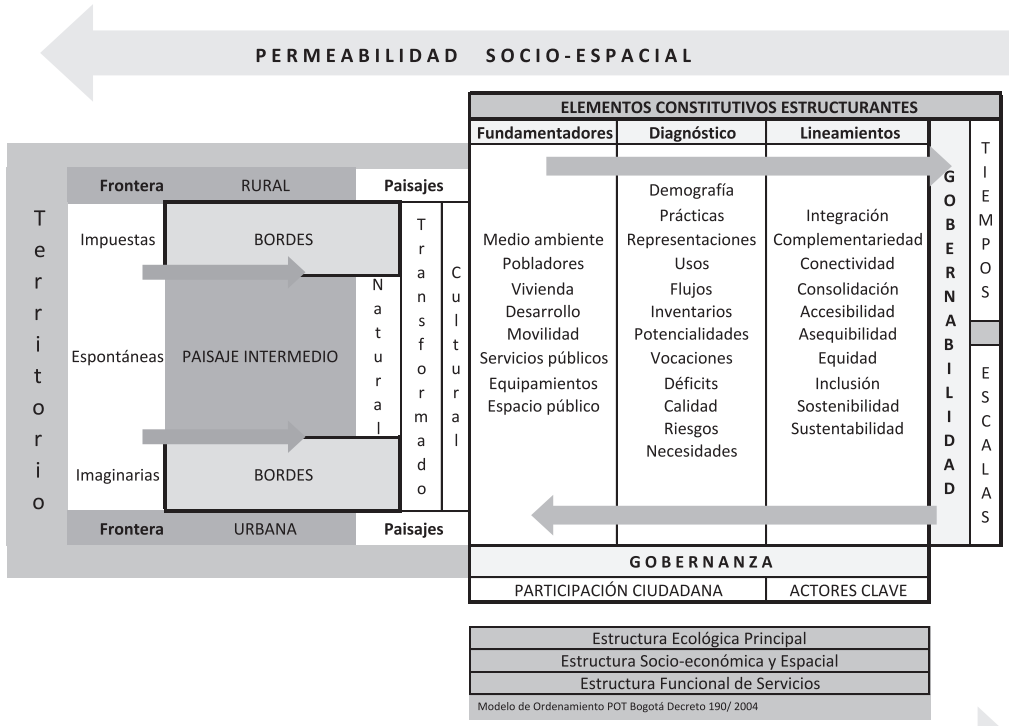

PERMEABILIDAD SOCIO-ESPACIAL

Elaboración propia.

Esto se articula, a su vez, con elementos constitutivos y estructurantes del territorio que se deben analizar (diagnóstico) desde sus diferentes escalas, realidades actuales, y necesidades futuras (tiempos), con el fin de determinar intervenciones basadas en lineamientos concertados para un adecuado desarrollo. Las estrategias resultantes deben surgir de y soportarse en sistemas de gobernabilidad (incluyendo el nivel metropolitano) y gobernanza adecuados como parte de una transversalidad y comunión holística a diversas escalas y temporalidades, donde la participación ciudadana y de actores clave (stakeholders) consoliden las realidades desde lo biótico, polí- 
tico, demográfico, socio-económico y cultural, y en las dimensiones territoriales requeridas para lograr sostenibilidad y sustentabilidad. Al cruzar lo anterior con el POT de Bogotá y lo mencionado sobre la Estructura Ecológica Principal (EEP), la articulación queda amarrada a la política pública, gestión y gobernanza. Este tipo de instrumentaciones fundamentan el actuar.

Imagen 9. La estructura urbana de paisaje que hace falta.

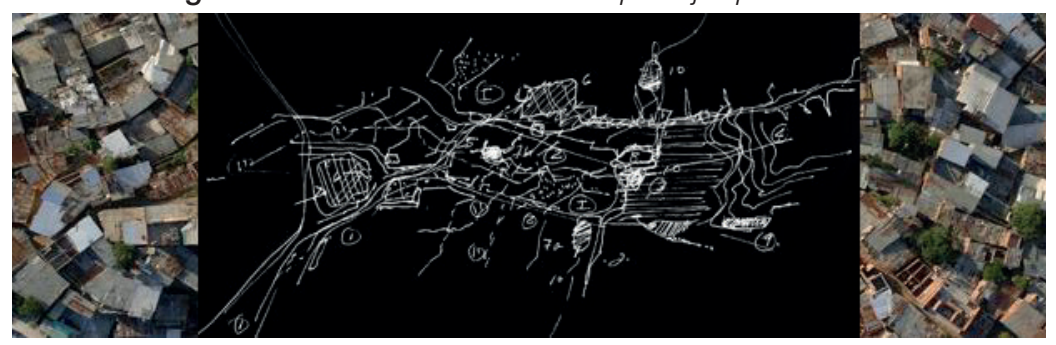

Imagen elaborada por D. Gouverneur.

\section{Aportes conclusivos.}

Este ensayo partió de la preocupante tendencia histórica -bien sea explícita o implícita- de permitir lo urbano expandirse en detrimento y a espaldas de lo rural. Esta postura otrora tolerada, hoy en ocasiones incitada, se enfrenta con el discurso internacional de promoción de la ciudad compacta, que denuncia los impactos y riesgos de la expansión urbana desaforada (Borsdorf, Hidalgo, y Vidal-Koppmann, 2016; UN-Habitat, 2016). Sin embargo, la 'nueva' apología de la ciudad densa, incluyente y sostenible no se acompaña de las correspondientes herramientas concretas para entender y actuar sobre el complejo desenvolvimiento territorial, especialmente en espacios de transición urbano-rural (DNP, 2013; UN-Habitat, 2016). Como aporte al estado del arte en esta materia, se plantea una ruta interpretativa de bordes y paisajes intermedios virtuales, existentes y resultantes, con el ánimo de estimular la reflexión en torno al manejo adecuado de dichos espacios, claves para la sostenibilidad y sustentabilidad territorial (ambiental, social, económica y política) (Gómez y Londoño, 2011; Gouverneur, 2016; Neu, 2016).

Los retos y desafíos son preocupantes. Los patrones de crecimiento urbano desordenados e informales resultado de una débil 
gestión pública y de prácticas especulativas han producido una trama desarticulada, segregacionista, fragmentada y disfuncional de bordes urbanos, espacios rurales e hibridaciones urbano-rurales, atentando contra el medio ambiente y la calidad de vida de los habitantes, con repercusiones para el conjunto de pobladores de áreas metropolitanas extendidas (Pillet, Cañizares, y Ruiz, 2010; Rosales, 2007). entretejido de fronteras impuestas, espontáneas e informales (que en ocasiones compiten o se superponen) ha complejizado el entendimiento de los procesos socio-culturales, económicos, ambientales y políticos que allí se desarrollan, carentes de un modelo claro de ordenamiento territorial soportado en una gobernabilidad metropolitana efectiva y gobernanza abierta a los diferentes actores públicos, privados y sociales del territorio (Escallier, 2006; Lozano, 2007; Dávila y Brand, 2012).

A esta problemática ampliamente conocida y documentada, se suman concepciones parciales y arcaicas de la ruralidad en cercanías urbanas, como un espacio vacío y expectante de la urbanización, dejando de lado las características y potenciales específicos que pudieran generar complementariedades en la planificación de territorios habitables y equitativos. "Se requieren otras categorías para pensar la sociedad, la ruralidad y las relaciones de los ciudadanos con el Estado" (Matijasevic y Ruiz, 1993, p. 28).

Este panorama aboga por renovadas miradas holísticas de los bordes y paisajes intermedios, desde diversas disciplinas y escalas, que partan y proyecten responsabilidad hacia el territorio, sus pobladores, entornos específicos y dinámicas propias. En este propósito, el urbanismo del paisaje ofrece interesantes perspectivas y herramientas que conjugan lo territorial y socio-cultural en la concepción de espacios funcionales y respetuosos con el entorno, mediante esquemas de crecimiento gradual y progresivo que garanticen la continuidad de los diferentes sistemas territoriales de acceso a bienes y servicios (ecológicos, viales y de transporte, servicios públicos, equipamientos y espacio público) (Gouverneur, 2016; Carta, 2017).

Dicho lo anterior, la configuración y tratamiento de regiones extendidas y áreas específicas, a partir de los bordes urbanos direccionados hacia los bordes rurales y viceversa, desde la integralidad de asumir el paisaje intermedio como elemento articulador entre uno y otro, ayuda a sistematizar las acciones desde los emprendimientos 
que surgen de estudios de desarrollo y gestión del territorio. Cuando, además, se adiciona la capacidad colectiva de influir en las realidades, opciones y oportunidades, así como sopesar escenarios de cambio 'abajo-arriba', se multiplica la posibilidad de fundamentar y concretar planes e intervenciones de desarrollo acordes y deseables (Alvarez y Rendón, 2010; Rosales, Brenner, y Mendoza, 2012).

"La paradoja tiene lugar en la utilización sin miramientos de herramientas modernas en el logro de sueños de transformación y también en las condiciones en las que tiene lugar el diálogo" (Vargas, 2016:434) entre los diversos actores y sus necesidades, requerimientos e imaginarios de renovación y apropiación del lugar, la región y el territorio. Insistiendo en este punto, las valoraciones tanto culturales como sociales y ambientales (sostenibilidad y sustentabilidad) deben ser parte integral de los procesos holísticos. De esta forma, la apropiación vincula las opciones socio-espaciales de pertenencia al imaginario formal del desarrollo (Rosales, Brenner, y Mendoza, 2012; Wolfrum y Frhr. v. Brandis, 2015; Vargas, 2016). Componentes tales como la espacialidad, la función y la materialidad acogen variaciones sustanciales sobre la cultura del lugar de forma tal que se privilegien las relaciones de formar espacios para la vida (Pérez, Vargas, Bautista, y Bohórquez, 2011; Wolfrum y Frhr. v. Brandis, 2015; Schröder, Carla, Ferretti, y Lino, 2017).

En síntesis, los principales aportes de este ensayo se condensan en la matriz presentada, o ruta interpretativa de los espacios de borde y paisaje intermedio, a manera de guía orientadora en la aproximación e intuiciones del territorio, como paso fundamental hacia la toma de decisiones de desarrollo y planificación territoriales, acertadas y efectivas. Se seguirá trillando sobre la importancia transversal de insertar, renovar y propiciar cambios socio-espaciales sin olvidar la importancia del desarrollo (socio-económico) como parte fundamental de la apropiación adecuada del territorio y su sostenibilidad ambiental. Obviamente, el relacionamiento a mayor escala está sujeto a las conexiones y soportes con el paisaje natural, sus recursos y preservación, y su sustentabilidad.

De manera coloquial y como inquietud final, se puede afirmar, que siempre se podrán ofrecer alternativas acordes a los hábitos y formas del habitar local con las que la población se sienta identificada y a gusto con su entorno. Pero esa es la tarea que aún no se hace, y que 
es parte de lo que David Gouverneur explicita en la imagen (Imagen 9) que abre este acápite final donde la labor es tejer la urdimbre de ese gran paisaje rur-urbano de manera armónica.

\section{Bibliografía}

Alfonso, O. A. (2010). "Profundización de las relaciones de metropolización de Bogotá con la Sabana." En Bogotá en el cambio de siglo: promesas y realidades, editado por Jaramillo S., 221-248. Quito: Colección de Ciudades.

Alcaldía Municipal de Madrid Cundinamarca. (2008). Plan de Desarrollo Municipal de Madrid Cundinamarca 2008-2012. Madrid, Cundinamarca, Colombia. Obtenido de file://Users/tn2/Downloads/pd\%20 -\%20madrid\%20.\%20cundinamarca\%20-\%20parte\%20i\%20-\%20 08\%20-\%2012.pdf

Alvarez, R., y Rendón, J. (2010). Recuperado el 9 de Marzo de 2015, de Universidad de la Rioja: http://Dialnet-ElTerritorioComoFactorDeDesarrollo-3417275.pdf

Augé, M. (2000). Los no lugares - Espacios del anonimato. Una antropología de la sobremodernidad. Barcelona: Gedisa

Batty, M., y Longley, P. (1994). Fractal Cities - A geometry of form and function. London: Academic Press Ltd.

Borja, J., y Castells, M. (1997). Local y Global - La gestion de las ciudades en la era de la información. Madrid: Santillana.

Borsdorf, A., Hidalgo, R., y Vidal-Koppmann, S. (Mayo de 2016). Habitat International. Recuperado el 10 de 08 de 2017, de Habitat International: Social segregation and gated communities in Santiago de Chile and Buenos Aires. A comparison

Carta, M. (2017). Planning for the rur-urban anthropocene. En J. Schröder, M. Carta, M. Ferretti, y B. Lino, Territories: Rural-urban strategies (pp. 36-53). Berlin: Jovis Verlag GmbH. 
Cortés, J. M. (Enero-Junio de 2012). Diversidad de realidades mutables: bordes urbanos en límites naturales. Traza(5), 120-145.

Cortés, R. (Enero-Diciembre de 2007). Del urbanismo a la planeación de Bogotá (1900-1990). Esquema inicial y materiales para pensar la trama de un relato. Revista Bitácora Urbano Territorial, 160-213.

Cuesta, A. (2013). Sistemas urbanos: entre lo contextual y lo autorreferencial. Bogotá: Universidad de La Salle.

DANE. (13 de Junio de 2003). Censo experimental de Soacha. Recuperado el 18 de Mayo de 2015, de Censo experimental de Soacha: www.dane.gov.co/files/prensa/comunicados/cp_censo_experim_soacha4.pdf

DANE. (2010). Censo general 2005 - Perfil Soacha, Cundinamarca. Departamento Administrativo Nacional de Estadística. Bogotá: DANE.

Dávila, J., y Brand, P. (2012). Movilidad urbana y pobreza. Medellín: Development Planning Unit, UCL / Universidad Nacional de Colombia .

Departamento Nacional de Planeación. (Diciembre de 2014). Departamento Nacional de Planeación. Recuperado el 16 de Agosto de 2017, de Departamento Nacional de Planeación: https://colaboracion.dnp.gov.co/CDT/Estudios\%20Econmicos/2015ago6\%20 Documento\%20de\%20Ruralidad\%20-\%20DDRS-MTC.pdf

DNP. (01 de Febrero de 2010). Elementos básicos sobre el Estado colombiano. Obtenido de dnp.gov.co: http://www.colombialider.org/ wp-content/uploads/2011/03/elementos-basicos-sobre-el-estado-colombiano-dnp-20101.pdf

DNP. (01 de 06 de 2013). Elementos para la formulación de la polîtica nacional de Ordenamiento Territorial y Alcances de las directrices departamentales . Obtenido de DNP: https://colaboracion.dnp.gov. co/CDT/Desarrollo\%20Territorial/Documento\%20PNOT-LOOT.\%20 DDTS\%20-\%20SODT.\%2011\%20junio\%20013.pdf

Echeverri, R. (Mayo de 2011). Cepal. Recuperado el 14 de Agosto de 2017, de Cepal: http://repositorio.cepal.org/bitstream/handle/11362 /3858/1/S2011960_es.pdf 
Empresa de Acueducto y Alcantarillado de Bogotá. (2003). El agua en la historia de Bogotá. Bogotá: Villegas Editores.

Escallier, R. (1 de Diciembre de 2006). Cahiers de la Méditerranée. Recuperado el 09 de Agosto de 2017, de Revues.org: file:///Users/tn2/ Downloads/cdlm-1473.pdf

Faiguenbaum, S. (05 de 2011). Cepal. Recuperado el 14 de Agosto de 2017, de Cepal: http://repositorio.cepal.org/bitstream/ handle/11362/3858/1/S2011960_es.pdf

Garayo, J. M. (1996). La sociedad rural en el final de siglo. Inguruak. Revista Vasca de Sociología y Ciencia Política(16), 61-79.

Giraldo, F. (1999). Ciudad y Crisis - ¿Hacia un nuevo paradigma? Bogotá: Tercer Mundo Editores.

Gómez, A., y Londoño, F. (2011). Paisajes y nuevos territorios. Barcelona: Anthropos.

González, J., Cardozo, M., Rivas, G., Ruíz, G., Castro, C., y Galvis, D. (2011). Circuitos, centralidades y estándar de vida Un ensayo de geografía económica. Bogotá: ODECOFI - Cinep.

Gouverneur, D. (2016). Diseño de nuevos asentamientos informales. Medellín: Fondo Editorial Universidad Eafit; Ediciones UniSalle.

Habitat, U. (2016). UNHabitat. Recuperado el 16 de Agosto de 2017, de UNHabitat: http://nua.unhabitat.org/uploads/WCRFullReport 2016_EN.pdf

Kay, C. (Septiembre de 2007). Algunas reflexiones sobre estudios rurales en América latina. (F. L.-S. Ecuador, Ed.) Iconos. Revista de Ciencias sociales(29), 31-50.

Kostov, S. (1991). The City Shaped - Urban Patterns and Meanings through history. Londres: Thames and Hudson Ltd.

Ley 1454 . (2011). Normas orgánicas sobre ordenamiento territorial. Bogotá: Congreso de Colombia. 
Lozada , H. (2000). Soacha: Plan de Ordenamiento Territorial. Academia de Ciencias Geograficas, 44(131), 1-12.

Lozano, K. M. (2007). El desarrollo local como método de análisis: los claroscuros de su complejidad. En R. Rosale, Desarrollo local: Teoría y preacticas socioterritoriales (pp. 99-121). México: Universidad Autónoma Metropolitana.

Lynch, K. (1980). Planificación del sitio. Barcelona: Editorial Gustavo Gili, S.A.

Martí Aris, C. (2000). Las formas de la residencia en la ciudad moderna. Barcelona, España: Edicions de la Universidad Politécnica de Catalunya, SL.

Martin-Barbero, J. (2000). Las transformaciones de mapa cultural: Una visión de América Latina. (26).

Matijasevic, M. T., y Ruiz, A. (Abril-Septiembre de 2013). La construcción social de lo rural. (E. sociológicos, Ed.) Revista Latinoamericana de Metodología de la Investigación Social, 3(5), 24-41.

Moreno, A. (2009). El proceso de conurbanción Bogotá-Soacha a través del estudio de la movilidad. Pontificia Universidad Javeriana, Facultad de arquitectuta y Diseño - Maestría en Planificación Urbana y Regional. Bogotá: Pontificia Universidad Javeriana.

Moreno, C. A., y Rubiano, M. (2014). Segregación residencial y movilidad cotidiana en el contexto metropolitano. Un estudio a partir de las relaciones Bogotá-Soacha. Territorios, 31, 133-162.

Moreno, O., y Peña, N. (2004). Formas de crecimiento Urbano Regional, en el caso de las localidades de Bosa, Ciudad Bolívar y Usme, y el municipio de Soacha. Bogotá: Universidad La Gran Colombia.

Mozas, J. (2011). El espacio público como campo de batalla. Independent magazine of architecture + technology (Autum), 6-19.

Neu, T. (2016). El Paisaje Intermedio: entre lo urbano y lo rural. Una franja de transición. Revista Opera, 19, 55-81. 
Panadero, M. (2010). Geografía humana y sotenibilidad. Hitos y perspectivas. En F. Pliiet, M. Cañizres, y R. Angel, , Paisaje y Sostenibilidad (49-86). Barcelona: Ediciones del Serbal.

Pérez, A., Ramos, H., Cuesta, A., Echeverría, N., y Muñoz, M. (2017). Calidad del hábitat - Planificación y producción habitacional en sectores de bajos ingresos económicos. Bogotá: Edicionaes Unisalle.

Pérez, E. (2004). El mundo rural Latinoamericano y la nueva ruralidad. Nómadas, 180-193.

Pérez, M., Vargas, F., Bautista, M., y Bohórquez, I. (2011). Pobladores y espacios rurales en la ciudad de Bogotá. Bogotá: Editorial Pontificia Universidad Javeriana.

Pillet, F., Cañizares, M., y Ruiz, A. (2010). Territorio, paisaje y sostenibilidad - Un mundo cambiante. Barcelona: Ediciones del Serbal.

Rendón, J. (Octubre de 2009). Industrialización y dinámicas espaciales en Bogotá: las urgencias de la gestión terriorial. Semestre Económico, 93-112.

Rengifo, J. A. (2012). Evolución de la planificación regional en Colombia "Tendencias y Perspectivas del desarrollo". XII Coloquio de Geocrítica 18. Bogotá: GEOCritica.

Rodríguez, J. C., y Salas, H. (Enero de 2004). http://educación.upa.cl/ revistaerural/erural.htm. Recuperado el 7 de Agosto de 2017, de Revista Digital eRural, Educación, cultura y desarrollo rural: http:// educación.upa.cl/revistaerural/erural.htm

Rosales, R. (2007). Desarrollo Local: Teoría y prácticas socioterritoriales. México: Universidad Autónoma Metropolitana.

Rosales, R., Brenner, L., y Mendoza, C. (2012). Geografía económica y social: Actores, instituciones y procesos globales. México: Siglo XXI Editores: Universidad Autónoma de México.

Rowe, P. (1991). Making a middle landscape. Cambridge: MIT Press. 
Rueda, N., de Angulo, L., Vila, P., y Barney, G. (1979). La autoconstrucion de vivienda urbana: Fundamentos para un enefoque analítico. Bogotá: Universidad de Los Andes.

Sabatini, F., y Salcedo, R. (Enero de 2007). Research Gate. Recuperado el 5 de Agosto de 2017, de Reserach gate: https://www.researchgate. net/publication/241724247_Gated_communities_and_the_poor_in_ Santiago_Chile_Functional_and_symbolic_integration_in_a_context_of_aggressive_capitalist_colonization_of_lower-class_areas

Salazar, C. (2016). Comprender para incidir. Bogotá: Ediciones Uniandes.

Salom, J. (2010). El territorio: escalas y estrategias. En F. Pillet, M. Cañizares, y A. Ruiz, Territroio, paisaje y sostenibilidad, 115-139. BarceIona: Ediciones del Serbal.

Schröder, J., Carla, M., Ferretti, M., y Lino, B. (2017). Territories: Rural-urban strategies. Berlin: Jovis Verlag $\mathrm{GmbH}$.

Shane, D. G. (2013). Recombinant Urbanism. West Sussex: John Wiley \& Sons Ltd.

Soja, E. (2000). Postmetropolis. Oxford: Blackwell Publishers.

Stephenson, B. (May de 2002). The roots of the New Urbanism: John Nolen's Garden City Ethic. Journal of planning history, 1(2), 99-123.

Thompson, I. (2014). Landscape architecture. Oxford: Oxford University Press.

Vargas, P. (2016). Historias de territorialidades en Colombia. Bogotá: Patricia Vargas Sarmiento.

Velázquez, F. (2010). La planeacion territorial en Colombia: contexto, trayectoria y experiencias. Cuadernos descentralistas No. 25, 1-192.

Wolfrum, S., y Frhr. v. Brandis, N. (2015). Performative Urbanism - Generating und designing urban space. Berlin: Jovis Verlag GmbH. 